\title{
Dissertation Summaries
}

Eleonora Dimela. Prefixation in Modern Greek dialects: synchronic and diachronic perspective. University of Patras, 2010.

[dimela@gmail.com]

\section{Keywords}

prefixation, morphology, grammaticalization, resemanticization, expansion of combinatorial properties, productivity.

\section{Introduction}

The subject of this study most generally is prefixation as it is realized in Modern Greek dialects. More specifically, though, I scrutinize the leftmost components of complex morphological form, in particular $\alpha \kappa \rho o-$ [akro], $\mu \omega \rho o_{-}$ [moro], $\pi \lambda \alpha \kappa o-\left[\right.$ plako], $\sigma \iota o_{-} / \sigma o-/ \sigma \alpha-[\mathrm{sjo}] /[\mathrm{so}] /[\mathrm{sa}]$ and $\chi \alpha \mu o-[\chi \mathrm{amo}]$. All of these derive from a lexical ancestor, and so their diachronic presence in the Greek language is studied, as well as their synchronic presence in the dialectal varieties of Modern Greek.

The examined data are completely dialectal in character. By selecting phenomena which do not occur in standard Modern Greek, I aim to provide a representative image of the way in which prefixation operates in Modern Greek dialects independently of the way in which equivalent procedures may work in the standard language. In addition, a dialectal approach gives the opportunity to study the transition from compounding to derivation, and in this case to prefixation.

The borderline between compounding and derivation is an extensively discussed topic of study within modern morphological theory (see among others Siegel 1979, Allen 1978, Aronoff 1976, Booij 1977, 2005, Lieber 1992, Scalise 1994, Ralli 1988, 2004, 2010, ten Hacken 2000, Bauer 2005 and Amiot 2005), as it involves word formation processes which show both similarities and differences. The data under examination offer the possibility of thorough discussion about this issue, as they constitute instances of grammaticalization, either fulfilled or in progress, in which the ancestor for the 
compounding prefix is not a preposition, but an autonomous lexical item, such as an adjective, a verb, an adverb or a noun.

\section{The Study}

Starting with a definition of the relation between compounding and derivation, and a determination of their basic characteristics, I observe the process of grammatical change of the examined morphemes, and their conversion from autonomous lexemes and parts of compounds, to attached prefixes and leftmost components of complex morphological forms. Relevant studies are found in bibliography: see among others Anastasiadi - Simeonidi 2008, Amiot 2005, van Goethem 2008a, 2008b, Stevens 2004, Giannoulopoulou 2006. The novelty of the present dissertation lies in its dual orientation, both synchronic and diachronic, and in the utilization of both written data (literature, notary and chronography texts, newspapers, questionnaires) and oral data (recordings, oral questionnaires), in order to investigate the phenomenon in each of its historical phases. The observation of every stage of the transition from compounding to prefixation (prefixization, cf. Amiot 2005) allows the suggestion of specific parameters which guide it, as well as their rating.

Considering the general criteria of grammaticalization (cf. Lehmann [1982] 1995 , Heine \& Kuteva 2002, 2005, 2007), we propose a triple set of parameters which control prefixization (phonological, semantic and morphological parameter). As a "hyponym" process of grammaticalization, which takes place within the domain (or phase, according to Lehmann 1995) of morphologization (see the conflicting views of Lehmann 1995 and Joseph 2003), prefixization shows similarities and differences from the general pattern regarding the parameters that control it.

The structure of the dissertation is as follows. The first chapter includes the limitation of the subject under research. In the second chapter, I carry out a review of the theoretical approaches in connection with prefixation, of the borderline between compounding and prefixation and also prefixization. In the third chapter I present a thorough description of dialectal data, as well as the methodology behind their selection. In the fourth chapter, I analyze the data on the basis of the parameters suggested above. In the fifth chapter, the parameters of prefixization are weighed, one against the other. I also deal with the relation of this specific process of grammaticalization (prefixization) with independent mechanisms of language change (analogy, reanalysis, lexicalization). Finally, in the sixth chapter, conclusions are drawn, from the entire dissertation, and novel matters for future research are proposed. 


\section{Conclusion}

I take a morphological approach to the data under examination, working within the framework of modern approaches to grammaticalization and recognizing as important the borderline, from a diachronic perspective, between compounding and derivation. In this way, my study highlights, through the correlation of the parameters mentioned above (phonological, semantic, morphological), the way in which these parameters combine and bring about the completion of prefixization of a morpheme. Also, the character of each parameter, and consequently of prefixization, is determined by its relation to broader phenomena of language change (analogy, reanalysis, lexicalization), which can work independently of grammaticalization, as well as by the relation of each to language-specific phonological, semantic and morphological peculiarities, and in this case those of Modern Greek. Especially since the research field is Modern Greek dialects, the analysis of data also serves to clarify the relation between dialects and broader linguistic theory.

Specifically, the general conclusions drawn by the present study are:

i. The phonological parameter, which concerns the phonological erosion of an item, does not have a steady presence in the process (see also Markopoulos 2009) and regularly occurs in its primary stages (contrary to Heine \& Kuteva 2007).

ii. The semantic parameter, which relates to the expansion to a more general and abstract meaning or/and polysemy, has an obligatory presence, but it cannot guarantee the completion of the process.

iii. The morphological parameter, which concerns the expansion of combinatorial properties and the productivity of the new forms, depends directly on the semantic parameter, and guarantees the transition from compounding to prefixation, as long as the two sub-parameters (expansion and productivity) occur. Structural opacity and decategorialization coincide with the result of the process and evidence its completion.

iv. Analogy and reanalysis are mechanisms - not factors - of prefixization (similar to Traugott's (2010) view of grammaticalization). Through analogy, on the one hand, new meanings for a leftmost component may arise, its morphological combinatorial properties may expand, or its use may be stabilized due to the creation of neologisms. Through reanalysis, on the other, restructuring of a morpheme into a prefixized structure is accomplished.

v. The general parameters of grammaticalization do not fully correspond with the suggested parameters (phonological parameter, semantic parameter, morphological parameter). Since prefixization in this case forms a 
process of change that takes place at the domain of morphology, an autonomous sector of grammar (cf. Scalise \& Guevara 2005), its peculiarities affect the development of the process. Therefore, the content and the rating of the suggested parameters reflect the domain as well as the language system in the frame of which the specific process of prefixization develops, as the latter does not necessarily presuppose all phases of grammaticalization.

vi. The factors that guide the way in which a prefixization process develops do not necessarily foreshadow its completion. The ensemble of specific parameters with a differentiated degree of effect on the process proves that the completion of the transition is not predetermined by one or more separate factors, but depends on their coincidence on partial phenomena.

Finally, when it comes to the relation of Modern Greek dialects with linguistic theory, I argue that it is a relation of interaction (see also Ralli 2009). Dialects can be considered as a fruitful domain of linguistic research and analysis, on the condition though that reliable and available sources and databases exist which can provide necessary support.

\section{References}

Allen, Margaret R. 1978. Morphological Investigations. Ph.D. Diss., University of Connecticut.

Amiot, Dany. 2005. Between compounding and derivation: Elements of word-formation corresponding to prepositions. In Wolfgang Dressler et al. (eds.), 183-195.

Anastasiadi - Simeonidi, Anna. 2008. The morpheme theo- in Greek [To morphima theo-stin Elliniki]. In Amalia Moser et al. (eds.), Glossis harin. Tomos afieromenos apo ton Tomea Glossologias ston Kathigiti Georgio Babinioti. Athens: Ellinika Grammata, 99-113.

Aronoff, Mark. 1976. Word Formation in Generative Grammar. Cambridge, MA.: MIT Press.

Bauer, Laurie. 2005. The Borderline between Derivation and Compounding. In Wolfgang Dressler et al. (eds.), 97-108.

Booij, Geert. 1977. Dutch Morphology. A Study of Word Formation in Generative Grammar. Lisse: Peter de Ridder Press.

Booij, Geert. 2005. Compounding and Derivation: Evidence for Construction Morphology. In W. Dressler et al (eds.), 109-132.

Dressler, Wolfgang U., Dieter Kastovsky, Oskar E. Pfeiffer, Franz Rainer (eds.). 2005. Morphology and its Demarcations: Selected papers from the 11th Morphology Meeting, Vienna, February 2004. Amsterdam/Philadelphia: John Benjamins Publishing Company.

Giannoulopoulou, Giannoula. 2006. On the borderline between the lexicon and grammar: confixes in Modern Greek and Italian. STUF 59: 270-283.

Heine, Bernd. 2003. Grammaticalization. In Brian D. Joseph and Richard D. Janda (eds.), Handbook of Historical Linguistics, 575-601. Oxford: Blackwell.

Heine, Bernd and Tania Kuteva. 2002. World Lexicon of Grammaticalization. Cambridge: Cambridge University Press.

Heine, Bernd and Tania Kuteva. 2005. Language Contact and Grammatical Change. Cambridge: Cambridge University Press. 
Heine, Bernd and Tania Kuteva. 2007. The Genesis of Grammar: a reconstruction. Oxford: Oxford University Press.

Joseph, Brian D. 2003. Morphologization from Syntax. In Brian D. Joseph and Richard D. Janda (eds.), Handbook of Historical Linguistics, 472-492. Oxford: Blackwell.

Lehmann, Christian. [1982] 1995. Thoughts on Grammaticalization. München - Newcastle. Lincom Studies in Theoretical Linguistics 01 (revised edition).

Lieber, Rochelle. 1992. Deconstructing Morphology. Chicago: The University of Chicago Press.

Markopoulos, Theodoros. 2009. The Future in Greek: From Ancient to Medieval. Oxford: Oxford University Press.

Ralli, Angela. 1988. Eléments de la morphologie du grec moderne. Ph.D. Diss. University of Montreal.

Ralli, Angela. 2004. Stem-based versus Word-based Morphological Configurations: The Case of Modern Greek Preverbs. Lingue e Linguaggio 2004 (2): 269-302.

Ralli, Angela. 2009. Morphology meets Dialectology: Insights from Modern Greek Dialects. Morphology 19(1): 87-105.

Ralli, Angela. 2010. Compounding versus Derivation. In Sergio Scalise and Irene Vogel (eds.), Cross-Disciplinary Issues in Compounding. Amsterdam/Philadelphia: John Benjamins Publishing Company, 57-74.

Scalise, Sergio. 1994. Morfologia. Bologna: Il Mulino.

Scalise, Sergio and Emiliano Guevara. 2005. The lexicalist approach to word-formation and the notion of lexicon. In Pavel Stekauer and Rochelle Lieber (eds.), The Handbook of Word Formation. Dordrecht: Springer, 144-188.

Stevens, Christopher M. 2004. The Prefixes and Prefixoids of Old Saxon: On the grammaticalization of the Old Saxon adverbs and prepositions. Leuvense Bijdragen 93: 151-178.

ten Hacken, Pius. 2000. Derivation and Compounding. In Geert Booij, Christian Lehmann, Joachim Mugdan, and Stavros Skopeteas (eds.), Morphologie - Morphology: Ein Handbuch zur Flexion und Wortbildung - A Handbook on Inflection and WordFormation. Berlin: de Gruyter, 1: 349-360.

Traugott, Elizabeth C. 2010. Grammaticalization. In Silvia Luraghi and Vit Bubenik (eds.), A Companion to Historical Linguistics, 269-283. London: Continuum Press.

van Goethem, Kristel. 2008a. The interaction between word structure and grammaticalization. Evidence from word-formation with French entre- and Dutch tussen-. Word Structure 1(1): 65-82.

van Goethem, Kristel. 2008b. Oud-leerling versus ancien élève: A Comparative Study of Adjectives Grammaticalizing into Prefixes in Dutch and French. Morphology 18: 27-49. 